\title{
EDUCAÇÃO DO CAMPO E O PARADIGMA DA EXTENSÃO DESCOLONIAL NA UNIVERSIDADE PÚBLICA
}

\section{LA EDUCACIÓN DE CAMPO Y EL PARADIGMA DE LA EXTENSIÓN DECOLONIAL EN LA UNIVERSIDAD PÚBLICA}

\section{RURAL EDUCATION AND THE PARADIGM OF DECOLONIAL EXTENSION IN THE PUBLIC UNIVERSITY}

\author{
Maria do Socorro Pereira da SILVA ${ }^{1}$
}

RESUMO: A educação pública brasileira enfrenta impasses na política de democratização da universidade com o desmonte da política educacional pelo governo ultraconservador. Essa política impacta no aumento da exclusão educacional dos povos do campo. Diante desse contexto, a educação do campo vem produzindo uma concepção de extensão popular que reafirma a valorização dos saberes dos camponeses na produção de uma educação libertadora. A extensão popular articula o diálogo entre conhecimento científico e popular no fortalecimento da pedagogia da alternância e na defesa da Educação do Campo. Interpelados pela problemática: como a extensão popular, no contexto da educação do campo, contribui com a descolonização da extensão universitária? A abordagem qualitativa e a investigação-ação participante fundamentam as bases metodológicas da pesquisa, com relação a análise dos dados utilizamos o método dialético. Os aportes teóricos que fundamentam a investigação: Freire (2006); Santos, (2010); Borda, (1981); Medeiros, (2010). Os resultados apontam para necessidade de descolonização da concepção de extensão acadêmica pelos princípios da extensão popular que se realiza pelo interconhecimento entre saberes científicos e saberes populares; articula novas bases teórico-metodológicas no trabalho educativo por meio de metodologias participativas. A extensão popular constitui os princípios para construção do conceito de extensão descolonial, que se efetiva pela intervenção ativa dos sujeitos do campo a partir de uma pedagogia participante que promove a descolonização do conhecimento e da universidade.

PALAVRAS-CHAVE: Universidade popular. Educação do campo. Política de educação. Universidade. Extensão descolonial.

RESUMEN: La educación pública brasileña enfrenta un impasse en la politica de democratización de la universidad con el desmantelamiento de la política educativa por parte del gobierno ultraconservador. Esta política tiene un impacto en incrementar la exclusión educativa de la gente del campo. En este contexto, la educación rural viene produciendo un concepto de extensión popular que reafirma la valorización del conocimiento de los campesinos en la producción de una educación liberadora. La extensión popular articula el diálogo entre conocimiento científico y conocimiento popular en el fortalecimiento de la pedagogía de la alternancia y en la defensa de la Educación Rural. Desafiado por el problema:

${ }^{1}$ Universidade Federal do Piaú (UFPI), Teresina - PI - Brasil. Professora Adjunta e Coordenadora do Núcleo de Estudos, Pesquisa e Extensão em Educação, Ciência Descolonial, Epistemologia e Sociedade (NEPEECDES). Doutora em Educação (UFPI). ORCID: https://orcid.org/0000-0003-3877-2420. E-mail: socorroprof@ufpi.edu.br

RIAEE - Revista Ibero-Americana de Estudos em Educação, Araraquara, v. 15, n. esp. 3, p. 2382-2395, nov., 2020. E-ISSN: 1982-5587 
¿cómo contribuye la extensión popular, en el contexto de la educación rural, a la descolonización de la extensión universitaria? El enfoque cualitativo y la investigación acción participativa son la base de las bases metodológicas de la investigación, con respecto al análisis de datos utilizamos el método dialéctico. La extensión popular, Freire (2015), en el proyecto de universidad popular moviliza a los sujetos del campo en la lucha por el derecho a la educación y la democratización de la universidad, Santos (2008), en articulación entre conocimiento científico y popular en la defensa de la Educación Rural. El enfoque cualitativo, la investigación-acción participativa, Borda (1981) y el análisis dialéctico, califican la metodología de descolonización de la universidad en la lucha por el derecho a la educación rural. Los resultados apuntan a la necesidad de descolonizar el concepto de extensión académica por extensión popular que busca valorar la interconocimiento entre el conocimiento científico y el conocimiento popular a partir de metodologías participativas. El concepto de extensión descolonial como práctica de participación activa de los sujetos de extensión como dimensión de la pedagogía participativa.

PALABRAS CLAVE: Universidad Popular. Educación rural. Política educativa. Universidad. Extensión decolonial.

ABSTRACT: Brazilian public education faces impasses in the university's democratization policy with the dismantling of educational policy by the ultraconservative government. This policy has an impact on increasing the educational exclusion of the people of the countryside. In this context, rural education has been producing a concept of popular extension that reaffirms the value of peasants' knowledge in the production of a liberating education. The popular extension articulates the dialogue between scientific and popular knowledge in the strengthening of the pedagogy of alternation and in the defense of the Education of the Field. Questioned by the problem: how does popular extension, in the context of rural education, contribute to the decolonization of university extension? The qualitative approach and the research-action participant base the methodological bases of the research, with relation to the analysis of the data we use the dialectic method. The popular extension, Freire (2015), in the popular university project mobilizes the rural subjects in the fight for the right to education and democratization of the university, Santos (2008), in articulation between scientific and popular knowledge in the defense of Rural Education. The qualitative approach, participatory action research, Borda (1981), and dialectical analysis qualify the university's decolonization methodology in the struggle for the right to rural education. The results point to the need to decolonize the concept of academic extension by popular extension that seeks to value the interknowledge between scientific and popular knowledge based on participatory methodologies. The concept of decolonial extension as a practice of active participation by extension subjects as a dimension of participatory pedagogy.

KEYWORDS: Popular university. Rural education. Education policy. University. Decolonial extension.

\section{O popular na luta pelo direito à educação do campo na universidade}

A Educação do Campo tem as marcas originais de um projeto de educação de ruptura com o paradigma da ciência hegemônica na universidade. É um giro epistemológico 
protagonizado pelos movimentos sociais do campo por uma política educacional de valorização dos sujeitos, dos contextos e dos saberes dos camponeses na luta pela Reforma Agrária no Brasil. Os movimentos sociais do campo reconhecem que na luta contra o latifúndio é necessário um projeto de educação contra-hegemônico ao capital extrativista que hegemoniza o modelo de desenvolvimento no campo.

Portanto, é uma ruptura epistemológica popular, pois: “Torna-se possível, assim, uma dupla operação de 'resgate' da epistemologia. Por um lado, esta deixa de estar confinada à reflexão sobre os saberes científicos [...]. A epistemologia passa a abranger explicitamente todos os saberes" (NUNES, 2010, p. 263). Essa ruptura de paradigma de educação democratizou a universidade na garantia do direito à educação superior pelos sujeitos do campo. É nesse contexto que se origina os cursos de licenciaturas em educação do campo na universidade.

Contudo, esse direito constitucional enfrenta um impasse diante das principais medidas do governo ultraconservador no Brasil, que publicamente é contra as políticas afirmativas de democratização da universidade e de valorização do ensino público superior. E, se acelera com a precarização da educação em suas condições estruturais e com cortes orçamentários de investimentos, contexto que impossibilita o avanço no acesso à universidade pelas classes populares e, de modo excludente, dos sujeitos do campo.

Essa realidade desafia os camponeses na reinvenção de sua prática educativa no processo de mobilização dos sujeitos populares do campo para defesa da recém criada política de educação do campo. E mais, exige um giro epistemológico nas estratégias de ação na luta pelo direito à educação a partir de processos de mobilização que se articulam pelo diálogo entre comunidade e universidade, entre saberes científicos e saberes populares, valorizando uma perspectiva de investigação-ação participante que reinvente a pedagogia da alternância e diálogo mobilizador entre o tempo universidade e o tempo comunidade como marcas da Educação do Campo.

Apesar desse potencial, que impasses e desafios a Educação do Campo enfrenta, no contexto da universidade, com relação às condições institucionais da UFPI para realização de suas ações educativas na metodologia da alternância? Qual o lugar da extensão popular na mobilização dos sujeitos do campo para defesa da educação do campo? Diante dessa questão, o Projeto Universidade Popular reafirma uma prática de extensão que se realiza pelo ensino e pesquisa a partir da articulação entre conhecimento acadêmico e conhecimento popular, fundamentado na formação humana que articula contexto acadêmico, movimentos sociais e os sujeitos do campo. 
Nesse estudo, discutimos sobre o lugar estratégico da extensão na educação do campo como possibilidade de mobilização dos sujeitos do campo pelo direito à educação no ensino superior, a partir das ações dos projetos que enfatizam o protagonismo dos sujeitos do campo na defesa de políticas educacionais de acesso e permanência na universidade, que passa pelo direito à terra e água no campo.

\section{Impasses da política em educação campo na democratização da universidade}

A extensão como lugar de mobilização social e construção coletiva do conhecimento para defesa de uma educação contextualizada e enraizada nos saberes do campo como possibilidade de construção de novos modos de produção do conhecimento e de ciência descolonial. A Universidade Popular, no contexto da Educação do Campo, é uma aposta necessária no processo de mobilização social dos sujeitos do campo, no fortalecimento da relação universidade e comunidade em tempo de medidas ultraconservadoras e cortes orçamentários às instituições de ensino superior.

Podemos iniciar afirmando que o Curso de Licenciatura em Educação do Campo na universidade pública é uma extensão ao contrário ${ }^{2}$ (SANTOS, 2010), pois se origina a partir da ocupação da universidade pelos sujeitos do campo, uma vez que sua proposta nasce nos movimentos sociais do campo, sendo que a primeira experiência na universidade foi o Pronera ${ }^{3}$. As marcas da relação comunidade e universidade estão inseridas na matriz metodológica da Pedagogia da Alternância, que se articula pela relação entre tempo universidade e tempo comunidade, como assevera Medeiros (2010, p. 10):

A proposta formativa toma como referência a unidade entre teoria e prática; assegurando o diálogo de saberes, não somente pela interdisciplinaridade, mas também pela ativação de conhecimentos não-disciplinares existentes nas comunidades e processos de lutas dos movimentos sociais, especialmente do campo.

Essa perspectiva metodológica confronta diretamente o modelo de universidade tradicional, pois implica em uma reorganização institucional para o atendimento das demandas administrativas de desenvolvimento da Educação do Campo. Ao contrário dos demais cursos,

${ }^{2}$ Extensão ao contrário, de fora da universidade para dentro da universidade. Consiste na promoção de diálogos entre o saber científico ou humanístico, que a universidade produz, e saberes leigos, populares, tradicionais, urbanos, camponeses, provindos de culturas não ocidentais (SANTOS, 2010, p. 176).

${ }^{3}$ Programa Nacional de Educação na Reforma Agrária (PRONERA) (MOLINA, 2003), celeiro das primeiras experiências de formação de educadores do campo no âmbito da educação superior com os cursos de Pedagogia da Terra.

RIAEE - Revista Ibero-Americana de Estudos em Educação, Araraquara, v. 15, n. esp. 3, p. 2382-2395, nov., 2020. E-ISSN: 1982-5587 
a Educação do Campo, no contexto da universidade, se organiza por uma ação direta com atualidade das questões sociais das comunidades e com a vida no campo como educação, recursos hídricos, questões agrárias, entre outras. Ou seja, existe um tempo de vivência e realização de atividades pedagógicas na comunidade.

Quer dizer, que apesar do potencial libertador e transformador da educação do campo enquanto política educacional, cuja metodologia valoriza a relação entre universidade e comunidade, seu desenvolvimento no cotidiano acadêmico tem sido um impasse em relação à lógica tradicional da universidade. Isso porque sua organização acadêmica tem como base um projeto político e pedagógico que se realiza pela alternância entre tempo universidade e tempo comunidade e, por vezes, a forma de organização institucional da universidade impossibilita as condições estruturais para realização adequada das atividades educativas de culminância da alternância.

Esse impasse revela, por um lado, que a política educacional na universidade exige uma reorganização institucional de suas rotinas administrativas, por outro lado, para os sujeitos do campo é uma proposta de ruptura no paradigma educacional no ensino superior. Manter a relação como a comunidade e a universidade, o diálogo entre saberes científicos e saberes populares é sem dúvidas uma tarefa da pedagogia da alternância que se estende à dimensão da extensão universitária.

Dito isso, podemos também afirmar o lugar estratégico da Universidade Popular, como projeto de extensão que fortalece a luta pela Educação do Campo, do interconhecimento entre comunidade e universidade. Desenvolve processos formativos visando a democratização do conhecimento, da ciência e de práticas educativas e pedagógicas no âmbito da universidade, tendo como fundamentos epistemológicos as metodologias participantes e não-extrativistas e os paradigmas de ciência descolonial.

A extensão descolonial promove o interconhecimento entre saberes científicos e saberes populares no fortalecimento de espaços de ciências e de conhecimentos na sociedade que estejam comprometidos com a garantia dos direitos de justiça social e de justiça cognitiva. $\mathrm{O}$ paradigma de universidade popular reafirma a democratização da universidade pública, portanto: "A ideia de 'universidade crítica', 'universidade multifuncional' e 'universidade diferenciada' [...]" (FERNANDES, 1989, p. 106), ou seja, uma perspectiva de extensão que reafirme a luta pela universidade e, ao mesmo tempo, valoriza uma política de educação do campo que respeite os tempos da vida no campo, em uma relação que afirme: 
O fortalecimento da relação universidade-sociedade que prioriza a superação das condições e desigualdades e exclusão existente. Através de projetos sociais, a universidade socializa seu conhecimento e disponibiliza seus serviços, exercendo sua responsabilidade social, ou mesmo sua missão: o compromisso com a melhoria da qualidade de vida dos cidadãos (NUNES; SILVA, 2011 p. 121).

Nesse sentido, Mora-Osejo e Borda (2004, p. 720), afirmam: "precisa-se de universidades participativas, comprometidas com o bem comum, em especial com as urgências das comunidades de base [...], de modo a favorecer a substituição de "definições discriminatórias entre o acadêmico e o popular"'". Nessa direção, os projetos extensão universitários podem ser uma ação estratégica de fortalecimento da pedagogia da alternância, pois procuram responder as interrogações sobre o sentido tanto da produção no mundo do trabalho camponês, quanto na socialização do conhecimento realizado na universidade que resulta do diálogo dos saberes com a comunidade.

Essa potência da extensão, na Educação do Campo, reafirma o popular da universidade pública para sua organização institucional para realização do tempo comunidade, pois exige uma estrutura diferente daquela necessária para o tempo universidade. Desse modo, a extensão é uma dimensão da universidade que fortalece os processos de mobilização dos sujeitos do campo na luta por educação, a partir das demandas sociais no campo, o que exige uma ação concreta da extensão. Assim, na perspectiva da universidade popular é necessário um testemunho concreto que se realiza pela ação da universidade na relação com as comunidades camponesas, pois não é uma atitude abstrata que transforma as condições sociais de exclusão dos sujeitos do campo. Paulo Freire nos diz com toda a razão, que:

conhecer não é o ato através do qual um sujeito transformado em objeto, recebe dócil e passivamente os conteúdos que outro lhe dá ou lhe impõe. $\mathrm{O}$ conhecimento pelo contrário, exige uma presença curiosa do sujeito em face do mundo. Requer sua ação transformadora sobre a realidade. Demanda uma busca constante. Implica invenção e reinvenção (FREIRE, 1996, p. 7).

A extensão, enquanto processo de mobilização dos sujeitos do campo e da universidade é um potencial, pois mantém uma leitura atual das questões sociais que vivenciam os sujeitos do campo. A extensão é uma aposta na democratização da universidade pública para uma ação de transformação social de sua responsabilidade com o desenvolvimento justo das populações que, historicamente, foram excluídas do direto à educação. Desse modo, a educação do campo em suas dimensões do ensino, pesquisa e extensão tem sido um instrumento educativo dos sujeitos do campo, da sociedade e do Estado para a implantação de uma política educacional que leve em consideração os contextos, os sujeitos e saberes das populações do campo. E, em 
igual sentido, na educação do campo, é necessário que sua prática educativa seja atualizada na defesa dos direitos dos povos do campo, baseada em uma educação libertadora, como estratégia de não adaptação ao sistema tradicional universitário e científico.

\section{Desafios da universidade popular na produção da extensão acadêmica}

A Universidade Popular é uma experiência fundamentada nos princípios da Educação Popular, que considera como dimensões formativas: a realidade social dos sujeitos populares, a pedagogia participante, a construção coletiva do conhecimento, a transformação do social e a afirmação de um projeto de sociedade de justiça social. É ao mesmo tempo, um projeto utópico de transformação da crise da universidade pública que tem sido marcada historicamente pela produção para lógica capitalista. Castro e Pereira (2008, p. 1646) afirmam, “É fundamental reiterar [...] uma educação superior de qualidade centrada em instituições universitárias que vinculem o ensino, a pesquisa e a extensão, promovendo uma inclusão social que mantenha a educação como um bem público inalienável”. É para essa lógica que a Universidade Popular por meio da extensão acadêmica se organiza para reafirmar o caráter público da universidade.

Essa postura se contrapõe à ciência hegemônica que desconhece os critérios de cientificidade da produção de conhecimento que se organiza sob a lógica dos saberes populares. A Universidade Popular busca o interconhecimento com os saberes populares, dando visibilidade a novos modos de produção do conhecimento. Enfatiza as tecnologias sociais alternativas produzidas pelos movimentos sociais, como a construção das cisternas que coletam água da chuva no inverno para abastecer milhares de famílias durante os longos períodos de seca no nordeste, desenvolvida pela Cáritas Brasileira em parceria com a Articulação do Semiárido (ASA); ou, ainda, os cursos de pedagogias do campo, desenvolvidos pelo Movimento Sem Terra (MST) como prática educativa de formação integral da população do campo em seus assentamentos e acampamentos, com forte incidência, na atualidade, no espaço acadêmico com a implantação dos cursos de licenciaturas em Educação do Campo.

Essas alternativas surgem em razão da crise da universidade como detentora do monopólio da produção do conhecimento. Por isso, quando nos propomos a discutir as crises da universidade para ressignificar o próprio sentido do popular da universidade pública, partimos de algumas considerações centrais: primeiro, enquanto o mundo eurocêntrico e o estadunidense discutem as crises da universidade, o mundo colonial lutava por um projeto de independência política dos domínios imperiais; em segundo lugar, considerando a velocidade com que a matriz "igualdade, fraternidade e liberdade" se traduz em emancipação social no 
mundo europeu, exigindo a construção de uma universidade centrada na produção de alta cultura, do outro lado da linha, no Sul do Mundo, as promessas da modernidade se reduziram na versão cristã de alfabetização e de uma educação dominante; terceiro aspecto, enquanto no capitalismo europeu e estadunidense as ideias de universidade se fundam na formação do estudioso e do intelectual detentor do conhecimento científico, a ideia de universidade no mundo colonial era traduzida na formação do "especialista" e do "profissional", preparando um operário com qualificação técnica e uma mão de obra para a produção capitalista.

Enquanto no norte do Mundo o Estado Liberal garantia a consolidação de uma universidade de alta tecnologia com avanços significativos no desenvolvimento desses continentes e de seus pares, em caminho inverso, no Sul do Mundo, a força do neoliberalismo e de governos ultraconservadores destituía o poder do Estado na construção de qualquer matriz de universidade democrática, marcada por um logo processo de sucateamento e de privatização do ensino público, marcando a crise da universidade brasileira:

A universidade está em crise em todo o Mundo. No Brasil, nós enfrentamos a crise pelo seu lado mais superficial, o da carência de recursos materiais e humanos. Na Europa, nos Estados Unidos e nos países em transição para o socialismo a crise assume outras polaridades. Diante desses paradigmas e dessas tendências, a nossa crise é moléstia de crescimento infantil e um impasse moral (FERNANDES, 1989, p. 82-84).

A crise da universidade no mundo, assume dimensões preocupantes no Brasil, pois tem historicamente forte impactos no processos de exclusão e de aprofundamento das desigualdades educacionais no acesso ao ensino superior, pelas classes populares. A universidade brasileira, tem reproduzido hegemonicamente as ideias de universidade norte-americana e eurocêntrica, como analisa Márquez (2014, p. 13): “A interpretação de nossa realidade com esquemas alheios só contribui para fazer-nos cada vez mais desconhecidos, cada vez menos livres, cada vez mais solitários. Talvez a venerável Europa fosse mais compreensiva se tratasse de nos ver em seu próprio passado". Por isso, a perspectiva do projeto de extensão Universidade Popular considera a formação humana e os saberes populares na produção do conhecimento científico ao se contrapor ao projeto excludente da produção científica para o capitalismo.

Os princípios da Investigação-Ação Participativa visam à superação da relação sujeitoobjeto, contrapõe-se à postura de neutralidade científica e coloca em causa a racionalidade que separa conhecimento científico e conhecimento popular, como enfatiza Borda (1981, p. 253254): 
Nossas ferramentas especiais de trabalho foram e são, em sua maioria, os referenciais e as técnicas com as quais sucessivas gerações de cientistas tentaram interpretar a realidade. Mas sabemos que essas ferramentas de trabalho não têm vida própria, mas tomam o significado que lhes damos; com seus respectivos efeitos em vários campos da vida e do conhecimento ${ }^{4}$.

Nesse sentido, o interconhecimento entre sujeitos do ambiente acadêmico e sujeitos dos movimentos sociais vem contribuindo para uma prática educativa de justiça social que aponta para a construção de uma epistemologia transgressora como matriz para uma ciência popular protagonizada pelas classes populares a partir de seus saberes e dos territórios pós-coloniais. A opção pela investigação-ação participativa coloca em questão a relação de hierarquia proclamada pela ciência hegemônica sujeito-objeto, restituindo os sentidos de interconhecimento a partir da dimensão sujeito-sujeito do conhecimento.

A sistematização da experiência pelos discentes é fundamental para retomada dessa dimensão compartilhada da produção do conhecimento, assim: "Os acadêmicos, por meio das metodologias ativas, expressaram sua capacidade de apreender os conteúdos, tiveram suas diferenças respeitadas e os docentes observando o aproveitamento" (DAMÁZIO; SOUZA, 2020, p. 1493). Nessa perspectiva, os docentes estimulam os discentes a pensarem suas comunidades e a relação com os saberes populares no processo de sistematização dos dados de campo, aprofundando o interconhecimento entre universidade e comunidade.

O Projeto Universidade Popular articula processos metodológicos participativos: a extensão se realiza por meio do Encontro de Experiências (Intercâmbio) envolvendo educadores dos movimentos sociais, docentes das universidades públicas e entidades parceiras para conhecimento de tecnologias sociais e práticas educativas comprometidas com a justiça social, tendo como ponto de essência a realização de Expedições Pedagógicas - espaços de vivências, conhecendo e analisando as experiências em educação popular e os novos modos de produção de ciência descolonial nos movimentos sociais, nas ONGs, no terceiro setor, entre outros.

A pesquisa, por meio do Estágio de Vivência Acadêmica, garantindo espaços de troca de experiências entre as instâncias e experiências organizativas nas universidades, conhecendo os núcleos de pesquisas, projetos de pesquisa e formas de interação universidade e sociedade; e o ensino, por meio de estudos organizados no Círculo de Cultura Popular, momento de aprofundamento teórico com aulas, seminários, grupo de estudo dirigido, debatendo temáticas

${ }^{4}$ Nuestras herramientas especiales de trabajo han sido y son mayormente los marcos de referencia y las técnicas con las que sucesivas generaciones de científicos han intentado interpretar la realidad. Pero bien sabemos que estas herramientas de trabajo no tienen vida propia, sino que toman el sentido que les demos; con sus respectivos efectos en variados campos de la vida y del conocimiento (BORDA, 1981, p. 253-254).

RIAEE - Revista Ibero-Americana de Estudos em Educação, Araraquara, v. 15, n. esp. 3, p. 2382-2395, nov., 2020. E-ISSN: 1982-5587 
corretas das pedagogias transgressoras e a ciência descolonial. Essas dimensões retomam: "O desafio de educar para a resistência parece justamente o desafio de saber como despertar a massa para o processo de formação enquanto emancipação, conquista de autonomia e adoção de pensamento crítico[...]" (AGOSTINI; SILVA, 2019, p. 1989). Isso implica, educar para seus contextos, suas realidades, suas afetividades, ou seja, educar para humanização.

\section{A extensão descolonial como metodologia da universidade popular na educação do campo}

A primeira fase das atividades da Universidade Popular foi o Encontro Regional de Experiências em Pesquisa e Extensão nos Movimentos Sociais na Universidade que aconteceu de 02 a 12 de maio de 2018, na cidade de Recife - PE. Participaram 40 (quarenta) pessoas entre estudantes, educadores e docentes da Universidade (UFPI, UFPE, UFRPE, UESPI e UFPB), Movimentos Sociais do Campo e da Cidade. A organização do evento pelo Projeto Universidade Popular teve como principal executora a Universidade Federal do Piaú - Curso de Licenciatura em Educação do Campo (CPCE), em parceria com a Escola de Formação Quilombo dos Palmares (EQUIP) e a Comissão Pastoral da Terra (CPT). As atividades de interconhecimento foram organizadas a partir da perspectiva da Investigação-Ação Participante.

As expedições pedagógicas são espaços de valorização dos saberes populares comprometidos com a pedagogia da formação para transformação social. A expedição pedagógica no SERTA ${ }^{5}$ e no Centro SABIÁ expressam como a sociedade organizada contribui para uma perspectiva de desenvolvimento sustentável através das Agroecologias e dos Sistemas Agroflorestais, como podemos perceber no registro das expedições:

Figura 1 - Visita a Comunidade Pedra Branca - Projeto Sabiá

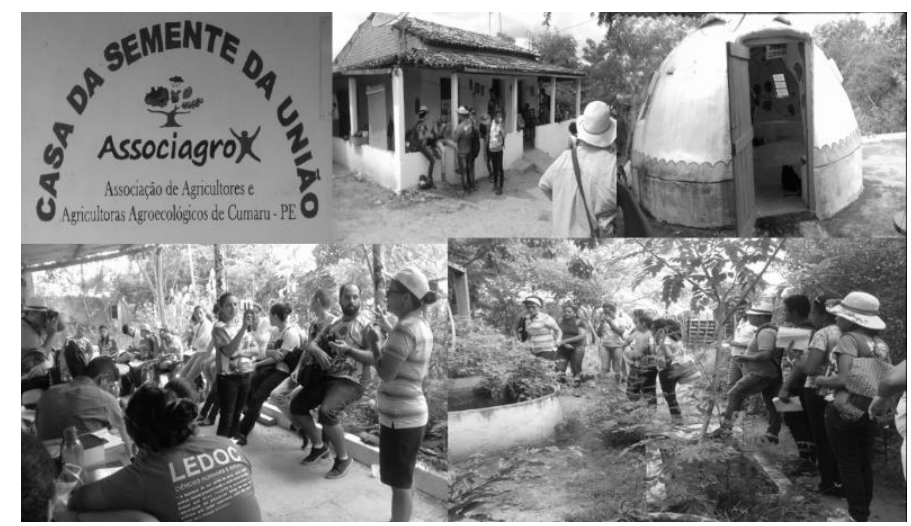

Fonte: Projeto de Extensão Cenas Camponesas (2018)

${ }^{5}$ Serviço de Tecnologia Alternativa (SERTA)

RIAEE - Revista Ibero-Americana de Estudos em Educação, Araraquara, v. 15, n. esp. 3, p. 2382-2395, nov., 2020. E-ISSN: 1982-5587 DOI: https://doi.org/10.21723/riaee.v15iesp3.14447 
A pedagogia ação-transformação é a realidade e a prática social dos sujeitos como lócus do conhecimento que se movimenta nas diversas áreas do conhecimento e nos fazeres dos sujeitos populares. A atividade de campo no Centro Sabiá e no Serta possibilitou conhecer os processos de auto-organização e autogestão comunitária, que mobilizam a comunidade para envolvimento em projetos comunitários a partir da Associação local, sendo a comunidade referência na produção de biodigestor, Cisterna Telhadão/Seriadão, Casa de Sementes e plantações orgânicas, visando a Segurança alimentar, energética e familiar.

Essas experiências fundamentam a segunda fase do projeto Universidade Popular, que tem como tema a sustentabilidade hídrica no Vale do Gurgueia, região dos cerrados no estado do Piauí, com foco nas nascentes dos brejos e no uso sustentável da água para produção da agricultura familiar.

Figura 2 - Pesquisadores na Expedição no assentamento tabocas, visita às roças

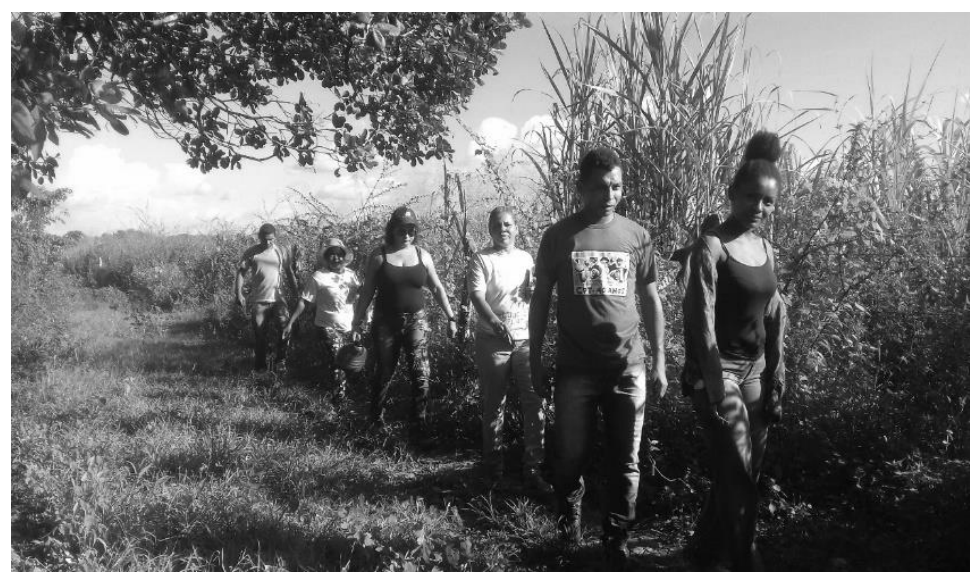

Fonte: Projeto de Extensão Universidade Popular (2019)

Essa expedição pedagógica descolonial discute a sustentabilidade hídrica no Sul do Piauí e a crise ambiental em razão do avanço do agronegócio. Revela os impasses na luta dos camponeses pelo território e os desafios de implantação de políticas públicas de proteção das nascentes dos brejos, a partir da experiência de proteção do Parque Nacional das Nascentes do Rio Parnaíba. O projeto mobiliza os discentes da educação do campo para visita técnicocientíficas para mapeamento das nascentes e das roças, plantações e vazantes às margens dos brejos e do rio Gurgueia. Essas duas experiências no Projeto Universidade Popular reafirmam os contextos do campo como espaço de conhecimento para além dos contextos acadêmicos.

Nesse sentido, os camponeses, a partir de sua relação com o meio ambiente e natureza, têm muito que ensinar à universidade, inclusive na ressignificação de seu caráter público com 
a necessidade de afirmação da dimensão popular, ao tempo que luta pelo direito de acesso à universidade e ao direito à educação.

\section{Conclusão}

A educação do campo, apensar dos impasses e desafios para seu desenvolvimento no contexto educacional universitário, tem protagonizado a formação dos camponeses, a visibilidade de seus contextos e saberes. A Universidade Popular, ao articular o interconhecimento entre saberes acadêmicos e saberes populares, postula o conceito de epistemologia transgressora que marca um processo sócio-histórico de ruptura política com o projeto de educação colonial e capitalista, mas, definitivamente, com o projeto de sociedade desumano e desigual a partir da prática social e dos saberes das classes populares e dos oprimidos que lutam pelo direito de acesso à educação e ao ensino superior.

A extensão descolonial, no contexto da educação do campo, reafirma a centralidade do protagonismo dos camponeses como sujeitos políticos, no processo de democratização da universidade no exercício de produção do conhecimento descolonial como possibilidade de refazer a estrutura social, política e epistemológica dominante, pois a estrutura do conhecimento oficial é também a estrutura da autoridade social. Desse modo, a Universidade Popular no contexto da Educação do Campo visa romper com a invisibilidade dos saberes populares, dos sujeitos e de seus contextos no sentido de articular novas lógicas de racionalidade e causalidade científicas fundamentadas nos princípios da pedagogia ação-transformação como aporte teórico-prático na construção de uma epistemologia transgressora e de uma ciência descolonial na reinvenção da universidade pública.

A Universidade Popular postula uma epistemologia transgressora enraizada nas metodologias participativas, nas técnicas de produção e na coleta de dados que se constituem na relação sujeito-sujeito do conhecimento, nas teorias do conhecimento que têm sido substanciadas nas práticas sociais dos próprios sujeitos. As ideias de ciência descolonial, a partir da relação entre os conhecimentos produzidos pelos movimentos sociais do campo e sua relação com a produção dos conhecimentos acadêmicos, são as marcas de defesa do sentido público da educação.

A extensão descolonial reafirma a luta e organização dos sujeitos populares do campo na luta pelo direito à educação pública de qualidade, de modo a superar os desafios de acesso à educação superior e aos processos de conhecimento que envolvem os saberes científicos e os saberes populares. A concepção educativa da Universidade Popular reafirma uma perspectiva 
popular camponesa como itinerário estratégico de democratização do sentido público da universidade e da ciência para outras ciências no mundo.

\section{REFERÊNCIAS}

AGOSTINI, N.; SILVA, L. B. O. Educação e formação crítica na atualidade. RIAEE Revista Ibero-Americana de Estudos em Educação, Araraquara, v. 14, n. esp. 4, p. 19771992, dez. 2019. Disponível em: https://periodicos.fclar.unesp.br/iberoamericana/article/view/12922/8691. Acesso: 12 jun. 2020.

BORDA, O. F. La ciência y el Pueblo: nuevas reflexiones sobre la investigación-acción. In: CONGRESSO NACIONAL DE SOCIOLOGIA, 3., 1981, Bogotá. Anais [...]. La sociologia em Colombia: balance y perspectivas. Asciación Colombiana de Sociologia. Bogotá, Colômbia, 1981.

CASTRO, A. M. D. A.; PEREIRA, R. L. A. Universidade flexível: nova tendência para as universidades federais brasileiras. RIAEE - Revista Ibero-Americana de Estudos em Educação, Araraquara, v. 14, n. esp. 3, p. 1638-1654, out. 2019. Disponível em: https://periodicos.fclar.unesp.br/iberoamericana/article/view/12738/8440. Acesso: 10 jun. 2020.

DAMÁZIO, M. F. M.; SOUZA, S. R. O. "Chão da sala de aula" no ensino superior: metodologia dos professores. Revista Ibero-Americana de Estudos em Educação, Araraquara, v. 15, n. esp. 2, p. 1482-1500, ago. 2020. Disponível em:

https://periodicos.fclar.unesp.br/iberoamericana/article/view/13801/9334. Acesso em: 10 set. 2020.

FERNADES, F. O desafio educacional. São Paulo: Cortez: Autores Associados, 1989. (Educação Contemporânea)

FREIRE, P. Extensão ou comunicação? São Paulo: Paz e Terra, 2015. 127 p.

MÁRQUEZ, G. G. A solidão da América Latina. IMEA-UNILA, Foz do Iguaçu, v. 2, n. 1, p. 12-14, 2014 Disponível em: https://revistas.unila.edu.br/IMEA-UNILA/article/view/251/247. Acesso em: 10. set. 2020.

MEDEIROS, L. B. Parceria e dissenso na educação do campo: marcas e desafios na luta do MST. Orientador: Danilo Romeu Streck. 2010. 243 f. Tese (Doutorado em Educação) Universidade do Vale do Rio dos Sinos, São Leopoldo, 2010.

MOLINA, M. C.; FERNANDES, B. M. O Campo da Educação do Campo. Educação do Campo: Contribuições para a Construção de um Projeto de Educação do Campo. Brasília, DF: Articulação Nacional "Por Uma Educação do Campo", 2004.

MORA-OSEJO, L. E.; BORDA, O. F. A superação do eurocentrismo. Enriquecimento do saber sistémico e endógeno sobre nosso contexto tropical. In: SANTOS, B. S. (Org.). Conhecimento prudente para uma vida decente. São Paulo: Cortez, 2004. p. 711-720. 
NUNES, A. L. F, SILVA, M. B. C. A extensão universitária no ensino superior e a sociedade. 2011. 15. Resumo. Minas Gerais, 2011. Disponível em:

http://www.uemg.br/openjournal/index.php/malestar/article/viewFile/60/89. Acesso em: 14 fev. 2019.

NUNES, J. A. O resgate da epistemologia. In: SANTOS, B. S.; MENESES, M. P. (Org.). Epistemologias do Sul. São Paulo: Cortez, 2010. p. 261-290.

SANTOS, B. S.; ALMEIDA, F. N. A Universidade no século XXI: para uma universidade nova. Coimbra: Almedina, 2008.

\section{Como referenciar este artigo}

SILVA, M. S. P. Educação do campo e o paradigma da extensão descolonial na universidade pública. Revista Ibero-Americana de Estudos em Educação, Araraquara, v. 15, n. esp. 3, p. 2382-2395, nov., $2020 . \quad$ E-ISSN: $1982-5587 . \quad$ DOI: https://doi.org/10.21723/riaee.v15iesp3.14447

Submetido em: 20/07/2020

Revisões requeridas em: 30/08/2020

Aprovado em: 29/09/2020

Publicado em: 30/10/2020 